\title{
Commentary
}

\section{Serrated Adenoma of the Colorectum}

\section{A Lesion with Teeth}

\author{
Jeremy R. Jass \\ From the Department of Pathology, McGill University, Montreal, \\ Quebec, Canada
}

Hypermethylation provides an important mechanism for inactivating tumor suppressor genes other than by mutation and loss. This epigenetic alteration occurs through methylation of cytosine bases within the promoter region of the affected gene. ${ }^{1}$ Cytosine bases occur within "islands" that are rich in cytosine-guanine (CpG) dinucleotides. A number of anonymous loci have been shown to be sensitive markers for the "CpG island methylator phenotype" (CIMP) and these are known as Methylated IN Tumors or MINTs. ${ }^{2}$

In a series of colorectal cancers, between $28 \%$ and $58 \%$ are "CpG island methylator phenotype" (CIMP) positive. ${ }^{2-4}$ CIMP-high status generally implies methylation in at least two MINTs or target genes such as $p 16$ when a small panel of such markers is used. The number of microsatellite instability-high (MSI-H) cancers in a series will influence the proportion that is CIMP positive. This is because the great majority of sporadic MSI-H cancers are CIMP positive. The definition and grading of CIMP positivity in terms of the number of markers that should be methylated has not been standardized. In a series of 16 MSI-H cancers that showed methylation of the DNA mismatch repair gene $h M L H 1$, all 16 (100\%) showed methylation of at least three MINTs out of a panel that included four MINTs: 1, 2, 12, and 31. When this stringent definition was applied to colorectal cancers that were not MSI-H, CIMP positivity was demonstrated in only 8 of $61(13 \%)$. However, a further 29 of 61 (47\%) non-MSI-H cancers showed methylation of one to two MINTs. ${ }^{5}$ Interestingly, extensively CIMP-positive cancers (with methylation of three or more MINTs but regardless of MSI status) show morphological and cytological differences from CIMP-low and CIMP-negative cancers. These differences comprise more tumor heterogeneity $(P<0.001)$, more extracellular mucin $(P<0.001)$, more intraepithelial lymphocytes $(P=$ $0.004)$, rounded nuclei $(P=0.015)$, vesicular nuclei $(P=$ 0.007 ), and a prominent nucleolus ( $P=0.012$ ). These observations suggest that the presence or absence of
DNA methylation is of major importance in determining the morphogenesis of colorectal cancer. ${ }^{5}$

In the study by Park et al published in the current issue of The American Journal of Pathology, ${ }^{6}$ CIMP status was explored in polyps of the colorectum. The polyps included 22 sporadic serrated adenomas, 34 sporadic tubular adenomas, and 6 serrated adenomas that presented in subjects with hyperplastic polyposis. Serrated adenomas were composed of dysplastic epithelium but with the sawtooth configuration that is typical of the hyperplastic polyp. ${ }^{7}$ Some had admixed traditional hyperplastic or adenomatous elements. DNA samples were extracted from microdissected paraffin sections. As well as using MINTs 1, 2 and 31 , and p16 to test for CIMP status, Park et al determined the MSI status of the lesions by using the mononucleotide markers BAT26, BAT40, and the polyA tract in TGFbetaRII. ${ }^{6}$ These DNA markers are highly sensitive and specific for MSI-H status.

Polyps with methylation of two MINT markers were defined as CIMP-high. Methylation was more frequent at all loci tested in samples derived from sporadic serrated adenomas as compared with tubular adenomas, but this reached statistical significance for only MINT1 $(P=$ $0.001)$ and MINT2 $(P=0.0001)$. Overall, CIMP-high status (implying methylation of at least two markers) was found in $68 \%$ of sporadic serrated adenomas but in only $18 \%$ of tubular adenomas $(P=0.0005)$. All five serrated adenomas that included admixed hyperplastic and conventional adenomatous components were CIMP-high whereas only $48 \%$ of pure serrated adenomas were CIMP-high $(P=0.052)$. Similarly, admixed polyps were more likely to be MSI-H (40\%) than pure serrated adenomas $(7 \%)$, though this was a non-significant trend because of low numbers. Additionally, sporadic serrated adenomas (18\%) were more frequently MSI-H than tubular adenomas (3\%), though this difference fell just short of statistical significance $(P=0.07)$.

Accepted for publication December 9, 2002.

Address reprint requests to Professor Jeremy R. Jass, Department of Pathology, McGill University, Duff Medical Building, 3775 University Street, Montreal, QC, H3A 2B4, Canada. E-mail: jeremy.jass@mcgill.ca. 
How can these findings be reconciled with the traditional view that places conventional adenomas and not serrated adenomas within the adenoma-carcinoma sequence? How many CIMP-positive cancers arise within serrated adenomas as opposed to traditional adenomas? Given the rarity of serrated adenomas, one could argue that only a tiny proportion of cancers could be expected to arise within serrated adenomas, regardless of whether the cancers were CIMP positive or not. In an unselected series of 18,000 colorectal polyps, only $0.6 \%$ were serrated adenomas. ${ }^{7}$ In a Japanese colonoscopic series, only $1.73 \%$ of adenomas were serrated adenomas. ${ }^{8}$ However, remnant serrated adenoma was detected in $5.8 \%$ of surgical resection specimens for colorectal cancer. ${ }^{9}$ In this study, an unknown number of cancers would have destroyed any associated precursor lesion. Therefore, the figure of $5.8 \%$ is likely to be an underestimate. The increased potential for malignant change is also evidenced by the high rate of intramucosal carcinoma $(11 \%)$ within the series of serrated adenomas documented by Longacre and Fenoglio-Preiser. ${ }^{7}$

Why should serrated adenomas have a relatively high propensity for malignant conversion? Many appear cytologically bland. In the series of 110 serrated adenomas reported by Longacre and Fenoglio-Preiser, ${ }^{7} 31$ were so bland that they were originally diagnosed as hyperplastic polyps. An important clue to the possible mechanism for rapid evolution is derived from the condition hereditary non-polyposis colorectal cancer (HNPCC). In this condition, there is evidence for a rapid transition from normal through adenoma to carcinoma. ${ }^{10}$ This accelerated tumorigenesis is driven by the state of genetic instability that results from loss of DNA mismatch repair proficiency. ${ }^{11}$ Methylation and loss of expression of the DNA mismatch repair gene $h M L H 1$ is implicated in sporadic MSI-H colorectal cancer. In the study of Park et al, methylation of $h M L H 1$ was demonstrated in two of four serrated adenomas that were $\mathrm{MSI}-\mathrm{H} .{ }^{6}$ This finding adds to a growing literature that implicates a hyperplastic polypserrated adenoma sequence in the pathogenesis of sporadic $\mathrm{MSI}-\mathrm{H}$ colorectal cancer and within the context of the methylator phenotype. ${ }^{12-14}$

Why is a methylator phenotype observed more frequently in serrated polyps than conventional adenomas? It is possible that methylation of a particular gene is implicated in the initiation of some serrated polyps, one candidate being the putative anti-adhesion/pro-apoptotic gene HPP1. ${ }^{15}$ If methylation of HPP1 occurs within a genetic or environmental background that potentiates DNA methylation in general, then it is likely that further gene silencing will occur through the same epigenetic mechanism. As pointed out by Park et al, ${ }^{6}$ both hyperplastic polyps and serrated adenomas are genetically highly heterogeneous. Some serrated polyps show DNA methylation and/or DNA microsatellite instability when others do not. ${ }^{16}$ Subsets of hyperplastic polyps may show K-ras mutation or $1 \mathrm{pLOH} .{ }^{17-19}$ Subsets of serrated adenomas may show K-ras mutation or TP53 mutation. ${ }^{20}$

A unifying two-step mechanism may explain much of the bewildering genetic variability in serrated polyps. ${ }^{21}$ The first step, implicating inhibition of apoptosis, could be explained by one of several mechanisms that include methylation of HPP $1^{15}$ or mutation of K-ras. ${ }^{22}$ It has been proposed that the second step, namely loss of a DNA repair mechanism, is only tolerated in cells that have already acquired a state of resistance to apoptosis. ${ }^{21}$ Without the priming step of apoptosis inhibition, the accumulation of DNA damage and/or DNA mismatches within normal cells would trigger apoptosis. The normal process of deleting cells that accumulate damaged DNA would explain the relatively rare finding of multiple neoplasms in subjects with HNPCC (in whom every cell carries a mutation in a DNA mismatch repair gene). In the case of the CIMP pathway, two DNA repair genes are known to be silenced by promoter methylation: hMLH1 and 0-6-methylguanine DNA methyltransferase (MGMT). ${ }^{23,24}$ Loss of expression of MGMT predisposes to the generation of methylG:T mismatches. The latter may trigger futile cycles of DNA repair that may ultimately cause chromosomal instability and apoptosis. ${ }^{25,26}$ Alternatively, however, the unstable mismatch site may be deleted. This would give rise to stable mutations that would be detected as low-level MSI (MSI-L). MSI-L occurs frequently in colorectal cancers with MGMT methylation. ${ }^{27}$

The spectrum of mutations occurring downstream of any loss of DNA repair proficiency will depend on the nature of the initiating step and the type of DNA repair process that is disrupted. With loss of $h M L H 1$, there will be mutation of genes with short intragenic repeats such as BAX, IGF2R, and TGFbetaRII. By contrast, mutation in $A P C, \mathrm{~K}-$ ras, and TP53 is infrequent, particularly in sporadic $\mathrm{MSI}-\mathrm{H}$ colorectal cancer. ${ }^{28}$ Loss of MGMT is associated with a relatively narrow spectrum of mutations, specifically $\mathrm{G}$ to $\mathrm{A}$ transitions in $\mathrm{K}-\mathrm{ras}^{29}$ and $\mathrm{C}$ to $\mathrm{T}$ transitions in TP53. ${ }^{30}$ Importantly, loss of expression of hMLH1 and MGMT has been demonstrated by immunohistochemistry in hyperplastic polyps, admixed polyps, and serrated adenomas. ${ }^{12-14,27,31}$ In the situation where K-ras mutation (say $G$ to $T$ ) serves as the initiating step that is subsequently followed by MGMT methylation, G to A mutation in K-ras would be predicted to be redundant and would not be observed as a clonal alteration.

A locus on $15 q$ (CRAC1) has been linked to an autosomal dominant precancerous condition in which serrated polyps as well as conventional adenomas are well represented. ${ }^{32}$ Some sporadic serrated adenomas show $15 \mathrm{qLOH} .{ }^{31}$ It may be predicted that the underlying gene located on chromosome $15 q$ will turn out to be implicated in the regulation of apoptosis. Therefore, loss of this gene would trigger an additional, independent serrated pathway to colorectal cancer. Given the finding of $1 \mathrm{pLOH}$ in a subset of hyperplastic polyps, ${ }^{18}$ a gene on chromosome $1 \mathrm{p}$ could be similarly implicated in the regulation of apoptosis. Passenger loss of MYH that is located on 1p32-34 might initiate genetic instability in resulting hyperplastic polyps that happen to occur in subjects who carry a pathogenic polymorphism in this DNA repair gene. ${ }^{33}$

The genetic variability that occurs in serrated adenomas is more than matched by morphological variability. ${ }^{20}$ Serrated adenomas may be sessile and flat with a tubular architecture; these closely mimic hyperplastic polyps. Serrated adenomas may also be protuberant with a tubulovillous or villous architecture; these may be confused 
with traditional tubulovillous or villous adenomas. Minor admixtures of hyperplastic and/or traditional adenomatous elements may be included within otherwise typical serrated adenomas. ${ }^{7}$ Some serrated adenomas arise within pre-existing hyperplastic polyps whereas others may represent serrated transformation within a pre-existing adenoma. Others, perhaps the majority, arise de novo. A transition from hyperplasia to dysplasia may occur within the microscopic hyperplastic lesions known as aberrant crypt foci. ${ }^{34,35}$ Villous adenomas are currently bracketed within the spectrum of colorectal adenomas. Formerly, colorectal adenomas were not considered as a spectrum but as three distinct lesions: adenomatous polyp (now termed tubular adenoma), papillary adenoma (now termed tubulovillous adenoma), and villous papilloma (now termed villous adenoma). There is evidence that at least some villous adenomas originate within preexisting hyperplastic polyps. ${ }^{36} \mathrm{~A}$ high frequency of CIMP within villous adenomas would support a re-grouping of this lesion with serrated polyps. The study by Park et al was limited to tubular adenomas. ${ }^{6}$ The data of Park et al ${ }^{6}$ add to earlier findings that associate DNA MSI with admixed polyps more than with pure serrated adenomas. ${ }^{37}$ The same tendency was observed for CIMP status, ${ }^{6}$ but the observations need to be extended in a larger series.

Serrated adenomas with particular patterns of genetic alterations would be expected to cluster within specific anatomical subsites within the colorectum. Most MSI-H cancers are CIMP-high and occur in the proximal colon. Serrated polyps that are MSI-H also show a predilection for the proximal colon. ${ }^{37}$ However, CIMP-positive colorectal cancers that are not MSI-H do not show a strong predilection for the proximal colon. Among CIMP-high (excluding MSI-H cases), CIMP-low and CIMP-neg colorectal cancers, $50 \%, 41 \%$, and $17 \%$ occurred in the proximal colon, respectively. ${ }^{5}$ The highest predilection for the proximal colon (88\%) is observed for colorectal cancers that are both CIMP-high and MSI-H. ${ }^{5}$ In the study by Park et al there was no association between CIMPhigh serrated adenoma and anatomical site. ${ }^{6}$ Nevertheless, no CIMP-negative serrated adenomas occurred in the proximal colon and most sporadic serrated adenomas in their study were not MSI-H. Serrated adenomas in subjects with hyperplastic polyposis were rarely CIMPhigh, but most of the subjects in their study had predominantly left-sided hyperplastic polyps. ${ }^{6}$ Concordant DNA methylation across multiple polyps (and all types of polyp) may occur in subjects with right-sided or pancolonic hyperplastic polyposis. ${ }^{16}$ This observation introduces the important concept of a generalized predisposition to DNA methylation, perhaps occurring on a hereditary basis. In turn, this would provide a novel explanation for multiple colorectal neoplasia.

While elements of this commentary remain speculative, it is not beyond the bounds of possibility that the serrated pathway could play more than a minor role in colorectal tumorigenesis. Glandular serration occurs most frequently in colorectal cancers that are either CIMP-high or CIMP-low. In a multivariate analysis adjusted for independent variables, this feature fell just short of statistical significance $(P=0.06) .{ }^{5}$ The finding of glandular serra- tion in a cancer does not prove an origin within a serrated precursor. On the other hand, critical analysis provides little evidence that the vast majority of colorectal cancers are initiated by APC mutation as indicated in the model that is now so widely promulgated in the scientific, clinical, and pathological literature. ${ }^{21}$ The adenoma-carcinoma paradigm serves as the guiding principle in programs supporting the screening and prevention of colorectal cancer. Yet we know from the lesson of familial adenomatous polyposis that an individual adenoma has a very low probability of evolving into cancer. Moreover, in three large, population-based, randomized controlled trials of fecal occult blood screening, adenoma removal resulted in little or no reduction in the incidence of colorectal cancer. ${ }^{38-40}$ The improvement in mortality in these trials was explained principally by the detection of more early stage cancers in the study groups. Pathologists are doubly responsible for correcting and modifying the status quo. First, it was investigators from the field of pathology who established and championed the exclusivity of the adenoma-carcinoma concept. Second, pathologists are ideally placed to establish the clinical, pathological, and molecular correlations that will inform viable, alternative hypotheses. A single adenoma with teeth may be more dangerous than one hundred adenomas of the toothless variety.

\section{References}

1. Baylin SB, Belinsky SA, Herman JG: Aberrant methylation of gene promoters in cancer: concepts, misconcepts, and promise. J Natl Cancer Inst 2000, 92:1460-1461

2. Toyota M, Ahuja N, Ohe-Toyota M, Herman JG, Baylin SB, Issa J-PJ: $\mathrm{CpG}$ island methylator phenotype in colorectal cancer. Proc Natl Acad Sci USA 1999, 96:8681-8686

3. Toyota M, Ohe-Toyota M, Ahuja N, Issa J-PJ: Distinct genetic profiles in colorectal tumors with or without the $\mathrm{CpG}$ island methylator phenotype. Proc Natl Acad Sci USA 2000, 97:710-715

4. Hawkins N, Norrie M, Cheong K, Mokany E, Ku S-L, Meagher A O'Connor T, Ward R: CpG island methylation in sporadic colorectal cancer and its relationship to microsatellite instability. Gastroenterology 2002, 122:1376-1387

5. Whitehall VLJ, Wynter CVA, Walsh MD, Simms LA, Purdie D, Pandeya N, Young J, Meltzer SJ, Leggett BA, Jass JR: Morphological and molecular heterogeneity within non-microsatellite instability-high colorectal cancer. Cancer Res 2002, 62:6011-6014

6. Park S-J, Rashid A, Lee J-H, Kim SG, Hamilton SR, Wu TT: Frequent $\mathrm{CpG}$ island methylation in serrated adenomas of the colorectum. Am J Pathol 2003, 162:815-822

7. Longacre TA, Fenoglio-Preiser CM: Mixed hyperplastic adenomatous polyps/serrated adenomas: a distinct form of colorectal neoplasia. Am J Surg Pathol 1990, 14:524-537

8. Matsumoto T, Mizuno M, Shimuzu M, Manabe T, lida M, Fujishima M Serrated adenoma of the colorectum: colonoscopic and histologic features. Gastrointest Endosc 1999, 49:736-742

9. Mäkinen MJ, George SMC, Jernvall P, Mäkelä J, Vihko P, Karttunen TJ: Colorectal carcinoma associated with serrated adenoma: prevalence, histological features, and prognosis. J Pathol 2001, 193:286294

10. Jass JR, Stewart SM: Evolution of hereditary non-polyposis colorectal cancer. Gut 1992, 33:783-786

11. Kinzler KW, Vogelstein B: Lessons from hereditary colorectal cancer. Cell 1996, 87:159-170

12. Jass JR, Young J, Leggett BA: Hyperplastic polyps and DNA microsatellite unstable cancers of the colorectum. Histopathology 2000 37:295-301

13. Jass JR, lino H, Ruszkiewicz A, Painter D, Solomon MJ, Koorey DJ, 
Cohn D, Furlong KL, Walsh MD, Palazzo J, Bocker Edmonston T, Fishel R, Young J, Leggett BA: Neoplastic progression occurs through mutator pathways in hyperplastic polyposis of the colorectum. Gut 2000, 47:43-49

14. Hawkins NJ, Ward RL: Sporadic colorectal cancers with microsatellite instability and their possible origin in hyperplastic polyps and serrated adenomas. J Natl Cancer Inst 2001, 93:1307-1313

15. Young JP, Biden KG, Simms LA, Huggard P, Karamatic R, Eyre HJ, Sutherland GR, Herath N, Barker MA, Anderson GJ, Fitzpatrick D, Ramm GA, Jass JR, Leggett BA: HPP1: a transmembrane protein commonly methylated in colorectal polyps and cancers. Proc Natl Acad Sci USA 2001, 98:265-270

16. Chan AO-O, Issa J-PJ, Morris JS, Hamilton SR, Rashid A: Concordant $\mathrm{CpG}$ island methylation in hyperplastic polyposis. Am J Pathol 2002, 160:529-536

17. Bomme L, Bardi G, Pandis N, Fenger C, Kronborg O, Heim S: Clonal karyotypic abnormalities in colorectal adenomas: clues to the early genetic events in the adenoma-carcinoma sequence. Genes Chromosomes Cancer 1994, 10:190-196

18. Rashid A, Houlihan S, Booker S, Petersen GM, Giardiello FM, Hamilton SR: Phenotypic and molecular characteristics of hyperplastic polyposis. Gastroenterology 2000, 119:323-332

19. Otori K, Oda Y, Sugiyama K, Hasebe T, Mukai K, Fujii T, Tajiri T, Yoshida S, Fukishima S, Esumi H: High frequency of K-ras mutations in human colorectal hyperplastic polyps. Gut 1997, 40:660-663

20. Jass JR: Serrated adenoma of the colorectum. Curr Diagn Pathol 2002, 8:42-49

21. Jass JR, Whitehall VLJ, Young J, Leggett BA: Emerging concepts in colorectal neoplasia. Gastroenterology 2002, 123:862-876

22. Fenton RG, Hixon JA, Wright PW, Brooks AD, Sayers TJ: Inhibition of Fas (CD95) expression and Fas-mediated apoptosis by oncogenic Ras. Cancer Res 1998, 58:3391-3400

23. Kane MF, Loda M, Gaida GM, Lipman J, Mishra R, Goldman H, Jessup J, Kolodner R: Methylation of the hMLH1 promoter correlates with lack of expression of hMLH1 in sporadic colon tumors and mismatch repair-defective human tumor cell lines. Cancer Res 1997, $57: 808-811$

24. Esteller M, Hamilton SR, Burger PC, Baylin SB, Herman JG: Inactivation of the DNA repair gene $\mathrm{O}^{6}$-methylguanine-DNA methyltransferase by promoter hypermethylation is a common event in primary human neoplasia. Cancer Res 1999, 59:793-797

25. Branch P, Aquilina G, Bignami M, Karran P: Defective mismatch binding and a mutator phenotype in cells tolerant to DNA damage. Nature 1993, 362:652-654

26. Karran P, Bignami M: DNA damage tolerance, mismatch repair, and genome instability. Bioessays 1994, 16:833-839

27. Whitehall VLJ, Walsh MD, Young J, Leggett BA, Jass JR: Methylation of O-6-methylguanine DNA methyltransferase characterises a subset of colorectal cancer with low level DNA microsatellite instability. Cancer Res 2001, 61:827-830
28. Jass JR, Young J, Leggett BA: Evolution of colorectal cancer: change of pace and change of direction. J Gastroenterol Hepatol 2002, 17:17-26

29. Esteller M, Toyota M, Sanchez-Cespedes M, Capella G, Peinado MA, Watkins DN, Issa J-PJ, Sidransky D, Baylin SB, Herman JG: Inactivation of the DNA repair gene $\mathrm{O}^{6}$-methylguanine-DNA methyltransferase by promoter hypermethylation is associated with $\mathrm{G}$ to $\mathrm{A}$ mutations in K-ras in colorectal tumorigenesis. Cancer Res 2000, 60: 2368-2371

30. Esteller M, Risques RA, Toyota M, Capella G, Moreno V, Peinado MA, Baylin SB, Herman JG: Promoter hypermethylation of the DNA repair gene $\mathrm{O}^{6}$-methylguanine-DNA methyltransferase is associated with the presence of $G: C$ to $A: T$ transition mutations in p53 in human colorectal tumorigenesis. Cancer Res 2001, 61:4689-4692

31. Sawyer EJ, Cerar A, Hanby AM, Gorman P, Arends M, Talbot IC, Tomlinson IPM: Molecular characteristics of serrated adenomas. Gut 2002, 51:200-206

32. Tomlinson I, Rahman N, Frayling I, Mangion J, Barfoot R, Hamoudi R, Seal S, Northover J, Thomas HJ, Hodgson S, Talbot I, Houlston R, Stratton MR: Inherited susceptibility to colorectal adenomas and carcinomas: evidence for a new predisposition gene on 15q14-q22. Gastroenterology 1999, 116:789-795

33. Al-Tassan N, Chmiel NH, Maynard J, Fleming N, Livingston AL, Williams GT, Hodges AK, Davies DR, David SS, Sampson JR, Cheadle JP: Inherited variants of MYH asociated with somatic G:C-T:A mutations in colorectal tumors. Nat Genet 2002, 30:227-232

34. Nascimbeni R, Villanacci V, Mariani PP, De Betta E, Ghirardi M, Donato F, Salemi B: Aberrant crypt foci in the human colon. Am J Surg Pathol 1999, 23:1256-1263

35. Chan AO-O, Broaddus RR, Houlihan PS, Issa J-PJ, Hamilton SR, Rashid A: CpG island methylation in aberrant crypt foci of the colorectum. Am J Pathol 2002, 160:1823-1830

36. Goldman H, Ming S, Hickok DF: Nature and significance of hyperplastic polyps of the human colon. Arch Pathol 1970, 89:349-354

37. lino H, Jass JR, Simms LA, Young J, Leggett B, Ajioka Y, Watanabe $\mathrm{H}$ : DNA microsatellite instability in hyperplastic polyps, serrated adenomas, and mixed polyps: a mild mutator pathway for colorectal cancer? J Clin Pathol 1999, 52:5-9

38. Hardcastle JD, Chamberlain JO, Robinson MH, Moss SM, Amar SS, Balfour TW, James PD, Mangham CM: Randomised controlled trial of faecal-occult-blood screening for colorectal cancer. Lancet 1996, 348:1472-1477

39. Kronborg O, Fenger C, Olsen J, Jorgensen OD, Sondergaard O: Randomised study of screening for colorectal cancer with faecaloccult blood test. Lancet 1996, 348:1467-1471

40. Mandel JS, Church TR, Bond JH, Ederer F, Geisser MS, Mongin SJ, Snover DC, Schuman LM: The effect of fecal occult-blood screening on the incidence of colorectal cancer. N Engl J Med 2000, 343:16031607 